\title{
POLYVINYLPYRROLIDONE AS A CORROSION INHIBITOR FOR CARBON STEEL IN A PERCHLORIC ACID SOLUTION: EFFECT OF STRUCTURAL SIZE
}

\author{
Abbes Benchadli ${ }^{1}$, TARIK AtTaR ${ }^{* 1,2}$, Boulanouar Messaoud ${ }^{1,2}$, and Esma \\ CHOUKCHOU-BRAHAM ${ }^{1}$
}

\author{
${ }^{1}$ Laboratory of Toxicomed, University Abou Beker Belkaid Tlemcen, BP 119, 13000 Tlemcen, ALGERIA
}

${ }^{2}$ Higher School of Applied Sciences Tlemcen, BP 165 RP Bel horizon, 13000 Tlemcen, ALGERIA

\begin{abstract}
Polymers are materials composed of macromolecules characterized by duplicates of smaller molecules that are covalently bonded together to provide a set of properties. Corrosion inhibition by such compounds is usually attributed to their adsorption on the metal-solution interface. The inhibition effect of different sizes of polyvinylpyrrolidone (PVP) on the corrosion of carbon steel (C-steel) in solutions of perchloric acid was investigated. The inhibition efficiency increases as the size of the inhibitor and its concentration increases, but decreases as the temperature increases and can reach a value of $81.53 \%$ and $5.0 \times 10^{-3} \mathrm{~mol} \mathrm{~L}^{-1}$ (PVP: $58,000 \mathrm{~g} \mathrm{~mol}^{-1}$ ) at $30^{\circ} \mathrm{C}$. The most remarkable inhibition efficiency was confirmed by the presence of the film formed on the metal surface by scanning electron microscopy. The kinetic and thermodynamic parameters for the corrosion of C-steel and adsorption of the inhibitor were determined and discussed. The combination of PVP with potassium iodide produced a strong synergistic effect on the inhibition of C-steel corrosion leading to a significant improvement in the inhibition efficiency. Quantum chemical parameters were studied using density functional theory to determine the possible relationship between the inhibitor and its electronic properties.
\end{abstract}

Keywords: Polyvinylpyrrolidone, Weight loss, Synergistic effect, SEM, DFT

\section{Introduction}

Despite its relatively limited corrosion resistance, carbon steel (C-steel) is widely used in chemical processing, nuclear and fossil fuel power plants, the oil and gas industries, construction and metal-processing equipment, mining, pipelines, transportation and marine applications. The corrosion of C-steel in acidic media is important because of its high mechanical properties and low cost [1]. Levels of corrosion increase rapidly after the failure of the preventive barrier and are followed by a number of reactions that change the properties as well as composition of the metal surface [2].

Generally speaking, a corrosion inhibitor is a compound that reduces or stops the rate of metal dissolution whenever introduced or added in small quantities to a corrosive environment by producing a preventive barrier film [3]. Moreover, a good corrosion inhibitor presents many characteristics such as high solubility, non-toxicity, biodegradability, stability, short- and long-term durability and low cost. The inhibition efficiency is often related to different variables like the structural chemistry and amount of the inhibitor in the medium, the nature of the metal and aggressive electrolyte as well as its $\mathrm{pH}$,

\footnotetext{
*Correspondence: att_tarik@yahoo.fr
}

temperature, and immersion time $[4,5]$.

Organic inhibitors mostly contain triple bonds, aromatic rings, and heteroatoms such as $\mathrm{O}, \mathrm{N}$, and $\mathrm{S}$ which are active centers for the adsorption process on the metal surface [6]. These atoms are characterized by higher basicity and electron density, thus act as corrosion inhibitors. Organic compounds behave as effective inhibitors due to their ability to be adsorbed onto the metal surface. Green corrosion inhibitors are drawing much attention in the field of corrosion because of their biodegradability, safety, renewability and ecological acceptability [7]. The mechanism of adsorption can be either physical or chemical as a result of the protective layer or adsorbed blanketing on the metal surface [8]. Chemical adsorption implies charge transfer or charge sharing from the adsorbate to the atoms of the metal surface in order to form a coordinate bond. The free energy of chemisorption is higher than that of physisorption. The latter type is due to electrostatic attraction between the inhibiting organic ions or dipoles and the electrically charged surface of the metal.

The use of polymers as corrosion inhibitors has attracted considerable attention recently because of their ability to form complexes with metal ions on the electrode surface. These complexes occupy a large surface, 
thus blanketing the metal surface and protecting it from corrosive agents present in the solution $[9,10]$. The applications of polyvinylpyrrolidone (PVP) are extensive in pharmaceutical, medicinal, cosmetics and industrial products [11]. It is used in food additives, adhesives, membranes, ceramics, paper, coatings and personal care products, e.g., toothpastes and shampoos, as well as in batteries, paints, environmental applications, etc. [12]. The PVP added to iodine $\left(\mathrm{I}_{2}\right)$ forms a complex called povidone-iodine (PVP-I) that is widely used in various products like liquid soaps, ointments, surgical scrubs and pessaries due to its antiseptic properties or as an antimicrobial and antibacterial agent in medical devices [13]. This complex is commonly known under the trade names of Wokadine, Pyodine, or even Betadine. Quantum chemistry calculations have been extensively used to explain experimental phenomena. They have proven to be very effective in evaluating the corrosion inhibition efficiency [14]. The conceptual density functional theory (CDFT) has been used to analyze the molecular activity of inhibitors [15].

The aim of the present work is to determine the effect of the size of polyvinylpyrrolidone compounds and their protection efficiencies on the corrosion of carbon steel in a solution of $1 \mathrm{M}$ perchloric acid by weight loss methods. The synergistic corrosion inhibition effect between PVP and potassium iodide (KI) was also investigated and the steel surface examined by scanning electron microscopy (SEM). Afterwards, quantum chemical calculations using DFT were performed to elucidate the interaction between the main constituents of PVP and the carbon-steel surface.

\section{Experimental}

\subsection{Material preparation}

Four forms of PVP polymers with molecular weights of $8,000,29,000,40,000$ and $58,000 \mathrm{~g} \mathrm{~mol}^{-1}$ and the vinylpyrrolidone monomer were purchased from SigmaAldrich. The blank solution was $1 \mathrm{M}$ perchloric acid prepared by diluting a concentrated solution of $\mathrm{HClO}_{4}$ (Sigma-Aldrich). The tested samples employed in this work and the chemical composition of C-steel are shown in Table 1.

\subsection{Preparation of the test sample}

Before conducting any tests, the samples of C-steel were mechanically abraded using different grades of emery paper, namely $100,400,600,800,1000$, and 1200 , before being washed with distilled water, degreased with acetone, air-dried then dipped into the corrosive or/and anticorrosive medium. These samples were used to study the loss in weight.

\subsection{Weight loss technique}

Weight loss techniques provide more realistic results with regard to uniform corrosion than electrochemical techniques because the experimental conditions simulate reallife conditions. Weight loss measurements of the C-steel samples were calculated in the solution of perchloric acid with and without the addition of different concentrations and molecular weights of polyvinylpyrrolidone. Loss in the weight of the specimen was resolved by measuring the difference in weight between the carbon-steel substrates before and after being placed in the acidic medium. Each sample was weighed by an electronic balance $( \pm 0.0001 \mathrm{~g})$ before being placed in the acid solution $(50 \mathrm{~mL})$. The immersion time was $2 \mathrm{~h}$ within the temperature range of $293-333 \mathrm{~K}$. The experiments were each performed three times and the average weight loss noted [16]. The corrosion rate $(\mathrm{CR})\left(\mathrm{mg} \mathrm{cm}^{-2} \mathrm{~h}^{-1}\right)$ was determined by [17]

$$
\mathrm{CR}=\left(m_{\mathrm{b}}-m_{\mathrm{a}}\right) / t S,
$$

where $m_{\mathrm{b}}$ and $m_{\mathrm{a}}$ denote the weight losses (mg) before and after being immersed in the acidic solution, respectively, $S$ stands for the total surface area of the specimen $\left(\mathrm{cm}^{2}\right)$, and $t$ represents the immersion time (h). The inhibition efficiency (IE) (\%) was calculated using [17]

$$
\mathrm{IE}=100\left(\mathrm{CR}^{\prime}-\mathrm{CR}\right) / \mathrm{CR}^{\prime}
$$

The degree of surface coverage $(\theta)$ which represents the part of the metal surface covered in inhibitor molecules was calculated using [17]

$$
\theta=1-\mathrm{CR} / \mathrm{CR}^{\prime}
$$

where $\mathrm{CR}^{\prime}$ and $\mathrm{CR}$ denote the corrosion rates of $\mathrm{C}$-steel samples in the absence and presence of polyvinylpyrrolidone, respectively.

\subsection{Synergism between inhibitors and iodide ions}

One potential method to cost-effectively increase the corrosion inhibition efficiency is to use the concept of synergism and employ a combination of inhibitors [18]. The synergism phenomenon in terms of corrosion inhibition results in an improvement in the capacity of the inhibitor

Table 1: Chemical composition of C-steel (wt. \%).

\begin{tabular}{|l|l|l|l|l|l|l|l|l|l|}
\hline $\mathrm{C}$ & $\mathrm{Mn}$ & $\mathrm{Cu}$ & $\mathrm{Cr}$ & $\mathrm{Ni}$ & $\mathrm{Si}$ & $\mathrm{S}$ & $\mathrm{Ti}$ & $\mathrm{Co}$ & $\mathrm{Fe}$ \\
\hline 0.370 & 0.680 & 0.160 & 0.077 & 0.059 & 0.023 & 0.016 & 0.011 & 0.009 & $\mathrm{Bal}$ \\
\hline
\end{tabular}


to resist corrosion in the presence of secondary compounds in the corrosive medium [19]. The presence of halide ions in acid media containing organic inhibitors has been found to stabilize the adsorption of organic cations, which leads to an increase in inhibition efficiency [20]. It has been shown that the synergistic effect of halide ions increases in the following order: chloride $\left(\mathrm{Cl}^{-}\right)<$bromide $\left(\mathrm{Br}^{-}\right)<$iodide (I) [21]. Iodide exhibited a higher synergistic effect compared to the other halide ions because of its large size and ease of polarization [22]. Therefore, the purpose of this study is to increase the inhibition efficiency by using iodide ions in a similar way to the synergistic effect with inhibitors tested with regard to the corrosion of C-steel in a solution of 1 M perchloric acid.

In order to determine the synergistic effect between inhibitors and iodide ions, the synergistic parameter $\left(S_{\theta}\right)$ was calculated from [23]

$$
S_{\theta}=\left(1-\theta_{\mathrm{PVP}+\mathrm{KI}}\right) /\left(1-\theta_{\mathrm{PVP}+\mathrm{KI}}^{\prime}\right)
$$

and

$$
\theta_{\mathrm{PVP}+\mathrm{KI}}=\left(\theta_{\mathrm{PVP}}+\theta_{\mathrm{KI}}\right)-\left(\theta_{\mathrm{PVP}} \times \theta_{\mathrm{KI}}\right),
$$

where $\theta_{\mathrm{PVP}}$ denotes the surface coverage of the PVP inhibitor, $\theta_{\mathrm{KI}}$ stands for the surface coverage of $\mathrm{KI}$, and $\theta_{\mathrm{PVP}+\mathrm{KI}}^{\prime}$ represents the combined surface coverage of $\mathrm{PVP}$ and $\mathrm{KI}$.

If $S_{\theta}$ is less than unity, this indicates an antagonistic effect which may lead to competitive adsorption and when $S_{\theta}$ approaches unity, the inhibitor compounds stop interacting with each other, whereas when $S_{\theta}$ is greater than unity, a synergistic effect exists between the selected inhibitors [24].

\subsection{Scanning electron microscopy (SEM)}

The surface morphology of the specimens of carbon steel was studied by SEM using a Hitachi TM1000 Tabletop scanning electron microscope at a scale of $100 \mu \mathrm{m}$ and magnification of $\times 1.0 \mathrm{~K}$. The samples were immersed in a solution of $1 \mathrm{M} \mathrm{HClO}_{4}$ and the effect of the inhibitors investigated. After $24 \mathrm{~h}$ of immersion under optimum conditions, the SEM images of both the polished specimens of carbon steel and those immersed in perchloric acid in the presence and absence of inhibitors were captured.

\subsection{Theoretical calculations}

The DFT method using the B3LYP/6-31G* approach was employed to test the quantum chemical calculations of the inhibitor using the Gaussian 09 program package. The values of the highest molecular orbitals $\left(E_{\mathrm{HOMO}}\right)$ and the lowest occupied ones ( $\left.E_{\mathrm{LUMO}}\right)$ were calculated. Other parameters such as electronegativity $(\chi)$, softness $(\sigma)$, global hardness $(\eta)$, electron affinity $(A)$ and the ionization potential $(I)$ were determined by Koopmans' theorem [25].
The HOMO energy is related to the ionization potential $(I)$, whereas the LUMO energy is dependent on the electron affinity $(A)$, as is shown in [26]

$$
A=-E_{\mathrm{LUMO}}, I=-E_{\mathrm{HOMO}} .
$$

The energy gap $(\Delta E)$ and global electronic chemical potential $(\mu)$ are determined from

$$
\Delta E=E_{\mathrm{LUMO}}-E_{\mathrm{HOMO}}
$$

and

$$
\mu=\frac{1}{2}\left(E_{\mathrm{LUMO}}+E_{\mathrm{HOMO}}\right),
$$

respectively $[27,28]$. Using the electron affinity $(A)$ and ionization potential $(I)$, the electronegativity $(\chi)$ and global hardness $(\eta)$ can be calculated from

$$
\chi=\frac{1}{2}(I+A)
$$

and

$$
\eta=\frac{1}{2}(I-A)
$$

respectively [29]. Global softness $(\sigma)$ demonstrates the capacity of an atom or group of atoms to receive electrons and is estimated from [30]

$$
\sigma=1 / \eta
$$

The electrophilicity index $(\omega)$ is calculated from $[31,32]$

$$
\omega=\mu^{2} / 2 \eta
$$

The number of electrons transferred $(\Delta N)$ was calculated from [33]

$$
\Delta N=\left(\chi_{\mathrm{Fe}}-\chi_{\mathrm{Inh}}\right) / 2\left(\eta_{\mathrm{Fe}}+\eta_{\mathrm{Inh}}\right),
$$

where $\chi_{\mathrm{Fe}}$ and $\chi_{\mathrm{Inh}}$ denote the absolute electronegativities of iron and the inhibitor, while $\eta_{\mathrm{Fe}}$ and $\eta_{\mathrm{Inh}}$ stand for the absolute hardness of iron and the inhibitor, respectively. The theoretical values $\left(\chi=7 \mathrm{eV} \mathrm{mol}^{-1}\right.$ and $\eta=0$ $\mathrm{eV} \mathrm{mol}^{-1}$ ) for iron were taken from the literature [34].

\section{Results and discussion}

\subsection{Effect of the acid medium}

Acidic solutions have been widely applied in industry, e.g., in the removal of mill scale from metal surfaces, acid pickling, acid descaling, acidizing oil wells and industrial acid cleaning. In the oil industry, the acidization of petroleum oil wells, an important stimulation technique, is used to enhance production [35]. $\mathrm{HCl}, \mathrm{HClO}_{4}$ and $\mathrm{H}_{2} \mathrm{SO}_{4}$ are the most applied acidic solutions because of their highly corrosive nature with regard to many metals and alloys even at low concentrations [36], whereas $\mathrm{HNO}_{3}$ and $\mathrm{H}_{3} \mathrm{PO}_{4}$ are used occasionally. In this study, the inhibition efficiencies of polyvinylpyrrolidone are mainly applied in different acid media such as perchloric acid, 


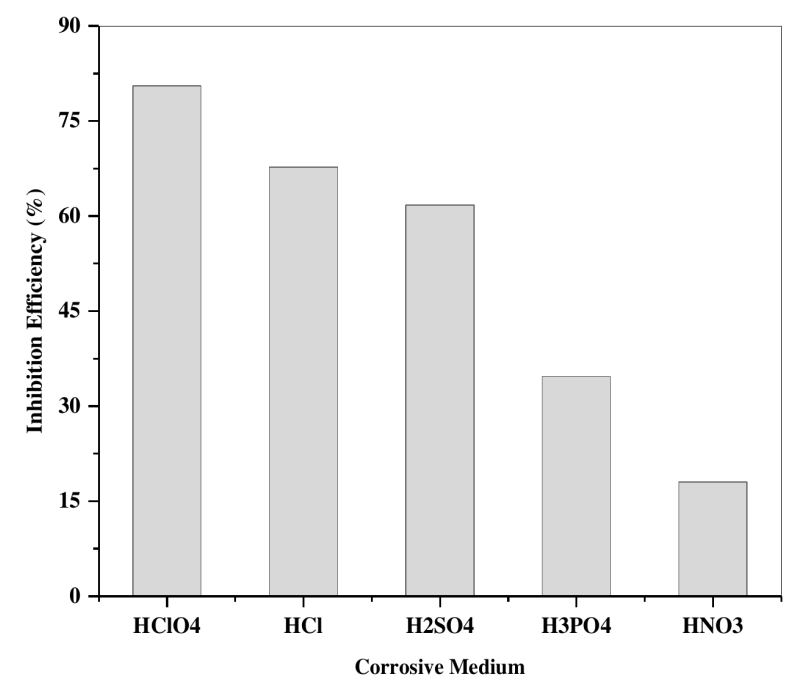

Figure 1: Variation in inhibition efficiency of carbon steel in different acid media (PVP: $58,000 \mathrm{~g} \mathrm{~mol}^{-1}$ with $1.0 \times 10^{-3} \mathrm{~mol} \mathrm{~L}^{-1}$ of acid medium for $2 \mathrm{~h}$ at $303 \mathrm{~K}$ ).

hydrochloric acid, sulfuric acid, phosphoric acid and nitric acid. According to Fig. 1, the best inhibition efficiency $(80.55 \%)$ is obtained in perchloric acid compared to hydrochloric acid $(67.74 \%)$, sulfuric acid $(61.71 \%)$, phosphoric acid $(34.68 \%)$ and nitric acid $(18.01 \%)$. This could be due to the beneficial adsorption of perchlorate ions on the C-steel surface.

The inhibitor molecules strongly interact with the metal surface in the presence of perchlorate ions due to the low coordination capacity of perchlorate ions. However, the coordination of chloride, sulfate, phosphate and nitrate ions with the metal surface render it less able to adsorb the inhibitor molecules. In this work, the study was conducted exclusively in perchloric acid because of the better adsorption of PVP in this acid compared to other acids that were tested.

\subsection{Effect of concentration and molecular weight}

The inhibition effect of PVP on the corrosion of carbon steel at $303 \mathrm{~K}$ in $1 \mathrm{M} \mathrm{HClO}_{4}$ as the corrosive medium was evaluated by a weight loss method. The effect of different molecular weights, namely the monomer and polymers of $8,000,29,000,40,000$, and $58,000 \mathrm{~g} \mathrm{~mol}^{-1}$, on the inhibition efficiency (IE) was studied. The dependence of the inhibition efficiency on the concentration as well as on the different molecular weights of PVPs is presented in Fig. 2. The improvement in the inhibition efficiency compared to the polymer concentration and molecular weight of PVPs suggests that more molecules are required to cover the metal surface when the concentration of the inhibitor is low. No further increase in IE beyond $10^{-3} \mathrm{~mol} \mathrm{~L}^{-1}$ of different molecular weights of PVP is attributed to the saturation of the adsorption process.

The experimental results prove that the PVP with a molecular weight of $58,000 \mathrm{~g} \mathrm{~mol}^{-1}$ is more effective

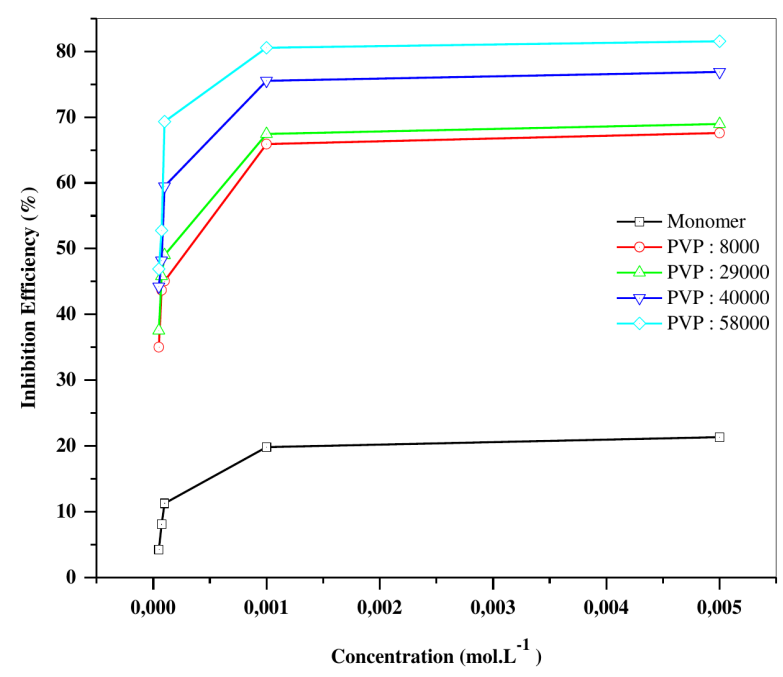

Figure 2: Variation in the inhibition efficiency against concentration in a $1 \mathrm{M} \mathrm{HClO}_{4}$ solution, using various molecular weights of the inhibitor.

in inhibiting the corrosion of C-steel in the aggressive medium than any other molecular weight of PVP at all concentrations. The monomer presents the least corrosion inhibition at all the concentrations studied and reaches a maximum efficiency of $21.81 \%$ at $5 \times 10^{-3} \mathrm{~mol} \mathrm{~L}^{-1}$.

\subsection{Effect of immersion time}

The study of this parameter was conducted in order to avoid any confusion between the phenomenon of passivation which could occur if the dive time is very long and the inhibition rate of the inhibitors. The effect of the immersion time for all the inhibitors tested with regard to IE is shown in the results presented in Fig. 3. The inhibition efficiency is calculated from 1 to 24 hours in uninhibited $\mathrm{HClO}_{4}$ and in the presence of the optimum concentration of the monomer $\left(10^{-3} \mathrm{~mol} \mathrm{~L}^{-1}\right)$ and different molecular weights of PVP at $303 \mathrm{~K}$. It can be concluded that the inhibition efficiency increases as the immersion time lengthens due to the stability of the adsorbed layer on the surface of C-steel up until 2 hours of immersion at different concentrations and molecular weights of the inhibitors. The inhibition efficiency decreases from 80.55 $\%$ to $68.25 \%$ after immersion times of PVP58000 of 2 hours and 24 hours, respectively. This may be explained by the desorption of inhibitor molecules from the C-steel surface and the instability of the inhibitor film on the metal surface [37].

\subsection{Effect of temperature and activation en- ergy}

The effect of the temperature introduces many changes on the metal surface such as adsorption, desorption, rearrangement or decomposition of the inhibitor. The effect of the temperature and different molecular weights of PVP on the corrosion inhibition of C-steel in $1 \mathrm{M} \mathrm{HClO}_{4}$ 


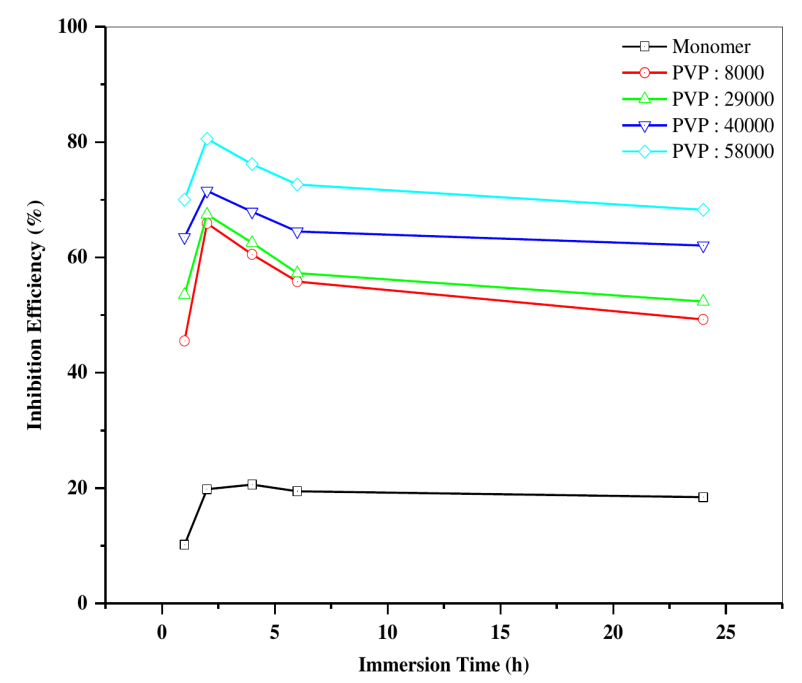

Figure 3: Variation in the inhibition efficiency against immersion time for carbon steel at various molecular weights of inhibition in a $1 \mathrm{M} \mathrm{HClO}_{4}$ solution.

was studied between 293 and $333 \mathrm{~K}$ to determine the dependence of the inhibition efficiency on the temperature and corrosion behavior of $\mathrm{C}$-steel in perchloric acid in the presence of inhibitors. According to the results presented in Table 2, at higher temperatures there is an appreciable decrease in the adsorption of the inhibitors on the metal surface leading to a rise in the corrosion rate.

At a temperature of $60^{\circ} \mathrm{C}$, the polyvinylpyrrolidone with a molecular weight of $58,000 \mathrm{~g} \mathrm{~mol}^{-1}$ showed a maximum inhibition efficiency of $69.41 \%$, while that of the monomer was only $6.35 \%$. Those for the other molecular weights of PVP, namely 8000, 29000, and $40000 \mathrm{~g} \mathrm{~mol}^{-1}$, were equal to $56.55,59.43$ and 63.81 $\%$, respectively, at the maximum tested concentration of $5 \times 10^{-3} \mathrm{~mol} \mathrm{~L}^{-1}$. An increase in the temperature of the solution reduces the inhibition effect by facilitating the counter-process of desorption [38]. The high rate of dissolution of C-steel in a $1 \mathrm{M} \mathrm{HClO}_{4}$ solution observed at elevated temperatures could be attributed to an increase in the dissolution energy effect acquired by the corrosive agent within the aggressive medium. Moreover, the desorption of the adsorbed inhibitor caused by enhanced agitation of the solution as a result of higher rates at which hydrogen gas evolves as the temperature rises is possible and can cause the capacity of the inhibitor to be adsorbed on the C-steel surface to be reduced [39]. For chemical adsorption, the inhibition efficiency is expected to increase as the temperature rises, but for physical adsorption, the inhibition efficiency is expected to decrease as the temperature increases [40]. The Arrhenius equation can be used to show the effect of the temperature on the inhibition performance of the studied compounds [41]:

$$
\mathrm{CR}=A \exp \left(-E_{\text {act }} / R T\right),
$$

where CR denotes the corrosion rate of carbon steel, $A$ stands for the pre-exponential factor of the Arrhenius equation, $E_{\text {act }}\left(\mathrm{kJ} \mathrm{mol}^{-1}\right)$ representsth e activation energy, $R$ refers to the gas constant $\left(8.314 \mathrm{~J} \mathrm{~mol}^{-1} \mathrm{~K}^{-1}\right)$ and $T$ is the temperature $(\mathrm{K})$.

The activation enthalpy $\Delta H_{\text {act }}$ and entropy of activation $\Delta S_{\text {act }}$ can be calculated by the following transition state equation [42]:

$$
\log \left(\frac{\mathrm{CR}}{T}\right)=\log \left(\frac{R}{N_{\mathrm{A}} h}\right)+\frac{\Delta S_{\mathrm{act}}}{2.3 R}-\frac{\Delta H_{\mathrm{act}}}{2.3 R T},
$$

where $R$ denotes the gas constant, $N_{\mathrm{A}}$ stands for Avogadro's number, and $h$ represents Planck's constant. A plot of $\log (\mathrm{CR} / T)$ against $1 / T$ yields a straight line with a gradient of $-\Delta H_{\text {act }} / 2.3 R$ and an intercept of $\left(\log \left(R / N_{\mathrm{A}} h\right)+\Delta S_{\text {act }} / 2.3 R\right)$ from which the values of $\Delta H_{\text {act }}$ and $\Delta S_{\text {act }}$ can be calculated as is presented in Table 3.

$\Delta G_{\text {act }}>0$, which means a non-spontaneous corrosion reaction, the rate of which increases as the concentration of the inhibitor increases [42]. The entropies of activation were negative in the absence and presence of inhibitors implying that a decrease in disorder occurred as the reaction proceeded. The higher activation energy of the process in the presence of an inhibitor compared to in its absence is attributed to its physisorption, whereas the opposite is a result of its chemisorption [43]. The positive values of the activation enthalpy in the presence and absence of different concentrations of the inhibitors reflect the endothermic nature of C-steel dissolution. This simply means that the dissolution process of steel is difficult [44].

\subsection{Adsorption isotherm}

The adsorption isotherms provide information about the interaction between the inhibitor and C-steel surface [45]. The type of interaction is related to the adsorption of inhibitor compounds as a result of chemisorption and physisorption [46]. It depends on many factors, e.g., the number of adsorption centers, mode of interactions with the metal surface, molecular weight and structure of the inhibitor. The data were used graphically using different isotherms such as Frumkin, Temkin and Langmuir. The Langmuir adsorption isotherm was found to best describe the adsorption. It can be seen that the results of the surface coverage in the presence of inhibitors are in good agreement with the weight loss technique (Eq. 3). The Langmuir adsorption isotherm model was employed using [47]

$$
\frac{C}{\theta}=\frac{1}{K_{\mathrm{ads}}}+C,
$$

where $\theta$ denotes the surface coverage by the inhibitor molecules, $C$ stands for the concentration, and $K_{\text {ads }}$ represents the equilibrium constant for the adsorptiondesorption process.

The value of the equilibrium constant obtained can be used to calculate the standard free energy by from [48]

$$
\Delta G_{\mathrm{ads}}=-R T \log \left(55.5 K_{\mathrm{ads}}\right),
$$


Table 2: The percentage inhibition efficiency of C-steel in $1 \mathrm{M} \mathrm{HClO}_{4}$ using five inhibitors tested between 293 and $333 \mathrm{~K}$.

\begin{tabular}{ccccccc}
\hline & $C\left(\mathrm{~mol} \mathrm{~L}^{-1}\right)$ & $293 \mathrm{~K}$ & $303 \mathrm{~K}$ & $313 \mathrm{~K}$ & $323 \mathrm{~K}$ & $333 \mathrm{~K}$ \\
\hline \multirow{4}{*}{ Monomer } & $5 \times 10^{-5}$ & 6.25 & 4.22 & 3.1 & 2.25 & 1.50 \\
& $1.5 \times 10^{-5}$ & 8.33 & 8.05 & 5.63 & 4.55 & 3.42 \\
& $10^{-4}$ & 15.5 & 11.25 & 8.1 & 6.6 & 4.2 \\
& $5 \times 10^{-3}$ & 20.65 & 19.81 & 10.43 & 8.7 & 6.15 \\
& $5 \times 10^{-3}$ & 21.97 & 21.34 & 10.5 & 8.78 & 6.35 \\
\hline \multirow{5}{*}{8,000} & $7.5 \times 10^{-5}$ & 43.37 & 35.01 & 24.17 & 16.85 & 10.19 \\
& $10^{-4}$ & 60.53 & 45.07 & 43.98 & 33.75 & 30.7 \\
& $10^{-3}$ & 78.2 & 65.9 & 62.2 & 58.85 & 56.42 \\
& $5 \times 10^{-3}$ & 78.46 & 67.59 & 62.35 & 58.95 & 56.55 \\
\hline \multirow{5}{*}{29,000} & $5 \times 10^{-5}$ & 45.5 & 37.55 & 29.24 & 19.31 & 12.23 \\
& $7.5 \times 10^{-5}$ & 62.51 & 45.81 & 41.21 & 25.93 & 21.54 \\
& $10^{-4}$ & 65.17 & 49.02 & 45.03 & 41.97 & 36.91 \\
& $10^{-3}$ & 82.17 & 67.44 & 64.61 & 61.35 & 59.39 \\
& $5 \times 10^{-3}$ & 82.12 & 68.95 & 64.68 & 61.42 & 59.43 \\
\hline \multirow{5}{*}{58,000} & $5 \times 10^{-5}$ & 50.18 & 44.22 & 36.86 & 22.16 & 15.95 \\
& $7.5 \times 10^{-5}$ & 66.57 & 48.21 & 45.13 & 28.18 & 23.73 \\
& $10^{-4}$ & 70.41 & 59.47 & 50.32 & 45.73 & 43.33 \\
& $10^{-3}$ & 84.09 & 75.53 & 70.88 & 68.41 & 63.6 \\
& $5 \times 10^{-3}$ & 84.27 & 76.86 & 70.9 & 68.54 & 63.81 \\
\hline & $5 \times 10^{-5}$ & 55.19 & 46.89 & 38.91 & 26.17 & 19.07 \\
& $7.5 \times 10^{-5}$ & 70.07 & 52.77 & 46.50 & 31.04 & 25.66 \\
& $10^{-4}$ & 75.23 & 69.33 & 58.53 & 52.72 & 48.71 \\
& $10^{-3}$ & 85.1 & 80.55 & 77.21 & 75.13 & 69.34 \\
& $5 \times 10^{-3}$ & 85.34 & 81.53 & 77.29 & 75.2 & 69.41 \\
\hline & & & & & &
\end{tabular}

Table 3: Thermodynamic activation parameters of the dissolution of carbon steel in $1 \mathrm{M} \mathrm{HClO}_{4}$ in the absence and presence of different concentrations and molecular weights of the inhibitors by applying Arrhenius and transition state plots.

\begin{tabular}{|c|c|c|c|c|c|}
\hline & $\begin{array}{c}C_{\mathrm{inh}} \\
\left(\mathrm{mol} \mathrm{L}^{-1}\right)\end{array}$ & $\begin{array}{c}E_{\text {act }} \\
\left(\mathrm{kJ} \mathrm{mol}^{-1}\right)\end{array}$ & $\begin{array}{c}\Delta H_{\mathrm{act}} \\
\left(\mathrm{kJ} \mathrm{mol}^{-1}\right)\end{array}$ & $\begin{array}{c}\Delta S_{\text {act }} \\
\left(\mathrm{J} \mathrm{mol}^{-1} \mathrm{~K}^{-1}\right)\end{array}$ & $\begin{array}{c}\Delta G_{\text {act }} 303 \mathrm{~K} \\
\left(\mathrm{~kJ} \mathrm{~mol}^{-1}\right)\end{array}$ \\
\hline $\mathrm{HClO}_{4}$ & 1 & 58.79 & 56.2 & -105.43 & 88.21 \\
\hline \multirow{5}{*}{ Monomer } & $5 \times 10^{-5}$ & 59.8 & 57.21 & -102.48 & 88.26 \\
\hline & $7.5 \times 10^{-5}$ & 59.81 & 57.22 & -102.66 & 88.31 \\
\hline & $10^{-4}$ & 61.08 & 58.48 & -98.88 & 88.44 \\
\hline & $10^{-3}$ & 61.99 & 59.39 & -96.27 & 88.55 \\
\hline & $5 \times 10^{-3}$ & 62.05 & 59.46 & -96.08 & 88.57 \\
\hline \multirow{5}{*}{8,000} & $5 \times 10^{-5}$ & 68.35 & 65.75 & -77.44 & 89.21 \\
\hline & $7.5 \times 10^{-5}$ & 69.69 & 67.1 & -74.13 & 89.56 \\
\hline & $10^{-4}$ & 69.53 & 66.94 & -75.84 & 89.91 \\
\hline & $10^{-3}$ & 71.74 & 69.14 & -72.78 & 91.19 \\
\hline & $5 \times 10^{-3}$ & 72.28 & 69.69 & -72.16 & 91.55 \\
\hline \multirow{5}{*}{29,000} & $5 \times 10^{-5}$ & 68.61 & 66.01 & -76.95 & 89.32 \\
\hline & $7.5 \times 10^{-5}$ & 73.42 & 70.82 & -63.04 & 89.92 \\
\hline & $10^{-4}$ & 69.61 & 67.02 & -76.33 & 90.14 \\
\hline & $10^{-3}$ & 73.83 & 71.23 & -66.83 & 91.48 \\
\hline & $5 \times 10^{-3}$ & 74.07 & 71.47 & -67.14 & 91.81 \\
\hline \multirow{5}{*}{40,000} & $5 \times 10^{-5}$ & 69.96 & 67.37 & -73.26 & 89.57 \\
\hline & $7.5 \times 10^{-5}$ & 74.95 & 72.38 & -58.54 & 90.11 \\
\hline & $10^{-4}$ & 71.86 & 69.27 & -70.24 & 90.55 \\
\hline & $10^{-3}$ & 74.45 & 71.86 & -66.34 & 91.96 \\
\hline & $5 \times 10^{-3}$ & 74.95 & 72.36 & -64.86 & 92.01 \\
\hline \multirow{5}{*}{58,000} & $5.0 \times 10^{-5}$ & 71.07 & 68.47 & -70.18 & 89.73 \\
\hline & $7.5 \times 10^{-5}$ & 76.77 & 74.18 & -53.27 & 90.32 \\
\hline & $10^{-4}$ & 74.21 & 71.61 & -64.18 & 91.05 \\
\hline & $10^{-3}$ & 72.53 & 69.94 & -74.07 & 92.38 \\
\hline & $5 \times 10^{-3}$ & 73.15 & 70.55 & -72.22 & 92.43 \\
\hline
\end{tabular}


Table 4: Thermodynamic parameters for the adsorption of five inhibitors on C-steel tested in a $1 \mathrm{M} \mathrm{HClO}_{4}$ solution at different temperatures.

\begin{tabular}{|c|c|c|c|c|c|}
\hline & $\begin{array}{l}T \\
(\mathrm{~K})\end{array}$ & $R^{2}$ & $\begin{array}{c}\Delta H_{\mathrm{ads}} \\
\left(\mathrm{kJ} \mathrm{mol}^{-1}\right)\end{array}$ & $\begin{array}{c}\Delta S_{\mathrm{ads}} \\
\left(\mathrm{J} \mathrm{mol}^{-1} \mathrm{~K}^{-1}\right)\end{array}$ & $\begin{array}{c}\Delta G_{\mathrm{ads}} \\
\left(\mathrm{kJ} \mathrm{mol}^{-1}\right)\end{array}$ \\
\hline \multirow[t]{7}{*}{ Monomer } & 293 & 0.999 & \multirow{5}{*}{-20.21} & 28.76 & -28.64 \\
\hline & 303 & 0.999 & & 28 & -28.7 \\
\hline & 313 & 0.999 & & 30.68 & -29.82 \\
\hline & 323 & 0.999 & & 29.93 & -29.88 \\
\hline & 333 & 0.999 & & 27.7 & -29.44 \\
\hline & 293 & 0.999 & \multirow{5}{*}{-37.15} & -9.42 & -34.39 \\
\hline & 303 & 0.999 & & -7.72 & -34.81 \\
\hline \multirow[t]{5}{*}{8,000} & 313 & 0.999 & & -8.79 & -34.4 \\
\hline & 323 & 0.999 & & -8.42 & -34.43 \\
\hline & 333 & 0.998 & & -9.13 & -34.11 \\
\hline & 293 & 0.999 & \multirow{5}{*}{-36.42} & -4.44 & -35.12 \\
\hline & 303 & 0.999 & & -3.99 & -35.21 \\
\hline \multirow[t]{5}{*}{29,000} & 313 & 0.999 & & -2.68 & -35.58 \\
\hline & 323 & 0.999 & & -4.18 & -35.07 \\
\hline & 333 & 0.998 & & -4.44 & -34.95 \\
\hline & 293 & 0.999 & \multirow{5}{*}{-35.27} & 1.09 & -35.59 \\
\hline & 303 & 0.999 & & 0.13 & -35.31 \\
\hline \multirow[t]{5}{*}{40,000} & 313 & 0.999 & & 2.81 & -36.15 \\
\hline & 323 & 0.999 & & 0.15 & -35.32 \\
\hline & 333 & 0.999 & & 1.05 & -35.62 \\
\hline & 293 & 0.999 & \multirow{5}{*}{-38.29} & -7.06 & -36.2 \\
\hline & 303 & 0.999 & & -6.91 & -36.18 \\
\hline \multirow[t]{3}{*}{58,000} & 313 & 0.999 & & -6.17 & -36.34 \\
\hline & 323 & 0.999 & & -7.74 & -35.77 \\
\hline & 333 & 0.999 & & -6.67 & -36.05 \\
\hline
\end{tabular}

where $R$ denotes the gas constant $\left(8.314 \mathrm{~J} \mathrm{~mol}^{-1} \mathrm{~K}^{-1}\right)$ and $T$ stands for the absolute temperature (K). The constant value of $55.5 \mathrm{~mol} \mathrm{~L}^{-1}$ is the concentration of water in dilute aqueous solutions.

The calculated changes in the enthalpy, entropy and free energy of adsorption are presented in Table 4. In this study, the negative values of the enthalpy of adsorption, which vary between -20.21 and $-38.29 \mathrm{~kJ} \mathrm{~mol}^{-1}$, indicate that the adsorption of the inhibitors on the C-steel is an exothermic process. High values of $\Delta G_{\text {ads }}$ show that the inhibitor is strongly adsorbed on the metal surface in the corrosive media. The negative values of the free energy of adsorption indicate that the adsorption of the inhibitors on the steel surface is spontaneous. The variation in $\Delta G_{\text {ads }}$ between -29.06 and $-36.34 \mathrm{~kJ} \mathrm{~mol}^{-1}$ indicates that the adsorption of inhibitors on the carbon steel surface in a solution of $1 \mathrm{M}$ perchloric acid at between 293 and $333 \mathrm{~K}$ is a mixture of chemical and physical adsorption. The determination of the free energy of adsorption provides information about the strength of adsorption of the molecules. Generally speaking, values of $\Delta G_{\text {ads }}$ between -40 and $-20 \mathrm{~kJ} \mathrm{~mol}^{-1}$ are consistent with physical adsorption, while those below $-40 \mathrm{~kJ} \mathrm{~mol}^{-1}$ are indicative of chemical adsorption [49].

\subsection{Synergistic effect}

Synergistic inhibition is brought about by the combination of PVP58000 and iodide ions for the corrosion of C-steel in $1 \mathrm{M} \mathrm{HClO}_{4}$ as halide ions have a greater tendency to be adsorbed on the surface as a result of their attraction to organic cations. The relationship between the efficiency and concentration of each inhibitor added by potassium iodide at different temperatures is shown in Table 5. The obtained results in the present study clearly show that the inhibition efficiency was substantially enhanced following the addition of KI and could occur because of the existence of synergism between different concentrations of the tested inhibitor and iodide ions.

The values of $S_{\theta}$ are higher than those for all concentrations indicating that the interaction between PVP and $\mathrm{KI}$ is a synergistic effect. It is well known that the maximum efficiency reaches $97.18 \%$ as a result of the synergistic effect, while for PVP in the absence of KI it is $85.34 \%$. The inhibition efficiency increased following the addition of potassium iodide ions due to the synergistic effect but decreased as the temperature rose. It has been concluded that more effective barrier films of inhibitor molecules are produced on the surface of the sample due to synergy, thus blocking the active sites on the steel surface to protect carbon steel from corrosion [50]. 
Table 5: Synergism parameter $\left(S_{\theta}\right)$ for different concentrations of PVP58000 and in the presence of a solution of $5 \times 10^{-6} \mathrm{M}$ $\mathrm{KI}$ from weight loss measurements at 293,313 , and $333 \mathrm{~K}$.

\begin{tabular}{c|ccc|ccc|ccc}
\hline $\mathrm{C}(\mathrm{mol} / \mathrm{L})$ & \multicolumn{3}{|c|}{$293 \mathrm{~K}$} & \multicolumn{3}{c|}{$313 \mathrm{~K}$} & \multicolumn{3}{c}{$333 \mathrm{~K}$} \\
& $\mathrm{IE}(\mathrm{PVP})$ & $\mathrm{IE}(\mathrm{PVP}+\mathrm{KI})$ & $S_{\theta}$ & $\mathrm{IE}(\mathrm{PVP})$ & $\mathrm{IE}(\mathrm{PVP}+\mathrm{KI})$ & $S_{\theta}$ & $\mathrm{IE}(\mathrm{PVP})$ & $\mathrm{IE}(\mathrm{PVP}+\mathrm{KI})$ & $S_{\theta}$ \\
\hline $5 \times 10^{-5}$ & 55.19 & 91.29 & 1.25 & 38.91 & 55.53 & 1.12 & 19.07 & 32.89 & 1.05 \\
$10^{-4}$ & 75.23 & 94.57 & 1.11 & 58.53 & 73.32 & 1.27 & 48.71 & 62.62 & 1.2 \\
$5 \times 10^{-3}$ & 85.34 & 97.18 & 1.26 & 77.29 & 83.68 & 1.14 & 69.41 & 74.92 & 1.07 \\
\hline
\end{tabular}

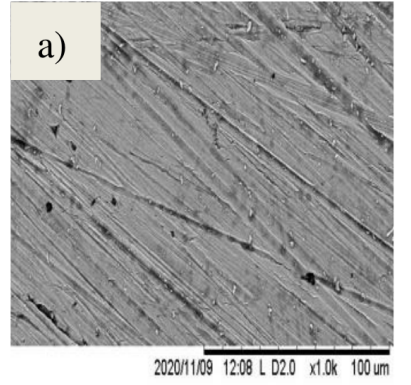

TM1000-FS UNRT-TLEMCEN

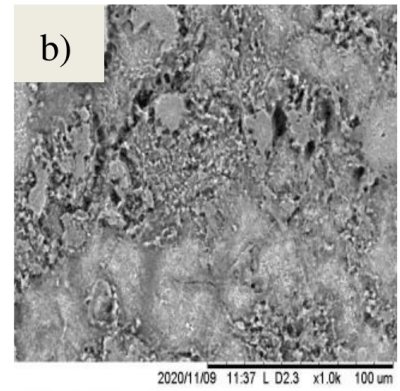

TM1000-FS_UniW-TLEMCEN

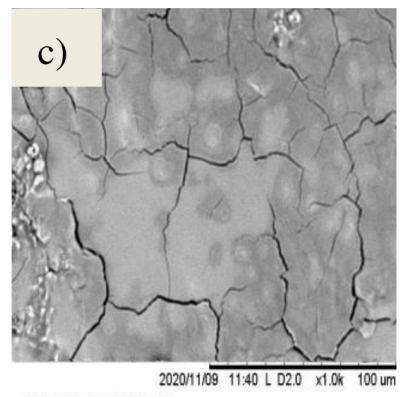

TM1000-FS_UNM-TLEMCEN

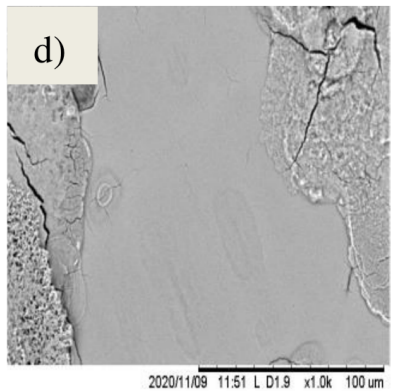

TM1000-FS UniWTLEMCEN

Figure 4: SEM images of carbon steel (a) before immersion, (b) after immersion in the acidic solution (1 $\left.\mathrm{M} \mathrm{HClO}_{4}\right)$ in the absence of inhibitors, (c) after immersion in the acidic solution containing $5 \times 10^{-3}$ M PVP58000, and (d): (c) + KI.
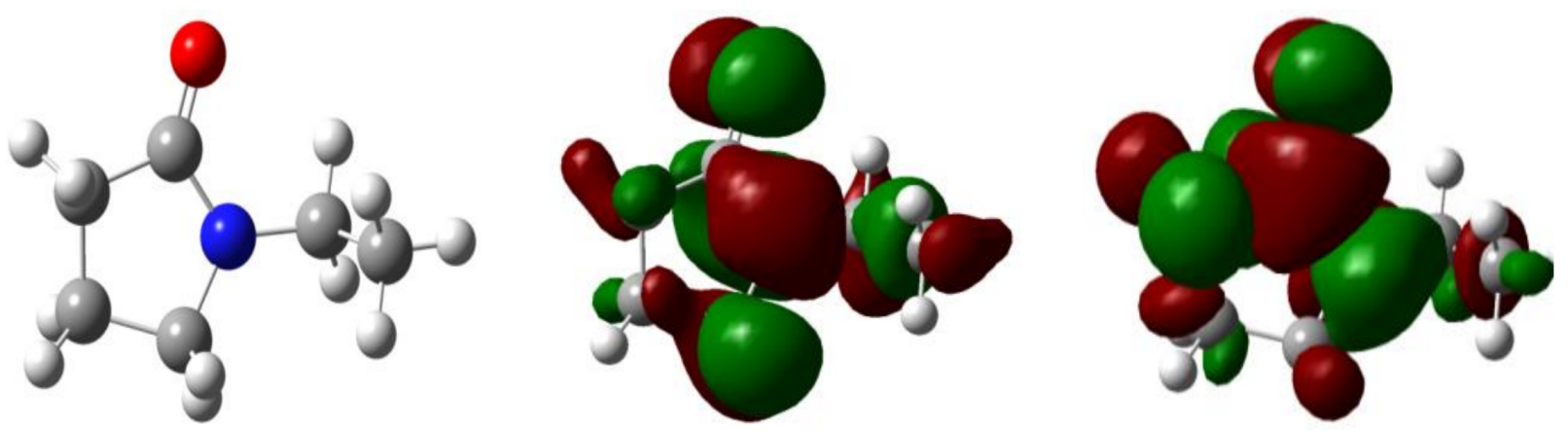

Figure 5: (a) Optimized molecular structure, (b) HOMO and (c) LUMO of the protonated Polyvinylpyrrolidone molecule.

\subsection{Scanning electron microscopy}

To confirm adsorption of the polyvinylpyrrolidone on the carbon-steel surface in the presence and absence of the inhibitor in $1 \mathrm{M} \mathrm{HClO}_{4}$, scanning electron microscopy experiments were carried out. Fig. 4a shows the surface morphology before corrosion testing. It is obvious that specimens immersed in the solution in the absence of PVP58000 and KI additives show significant degradation of the surface and pitting corrosion is evident from the surface morphology as is shown in Fig. 4b. However, in the presence of PVP, an obvious reduction in the degradation of the surface is shown. This amelioration can be attributed to the adsorption of PVP on the metal surface and the formation of a protective film, thereby isolating the carbon-steel surface (Fig. 4c). The addition of KI improves the degree of inhibition and the stability of the corrosion product on the steel surface as is shown in Fig. 4d. This indicates that the adsorption of iodide ions on carbon steel leads to the formation of more stable films. The scanning electron microscopy (SEM) study confirmed that the corrosion inhibition of carbon steel and synergistic effect occur following the adsorption of inhibitor molecules on the metal surface.

\subsection{Quantum chemical calculations}

The experimental study was completed by a theoretical study at the B3LYP/6-31G* level in order to correlate the results obtained experimentally with the molecular structure and electrical properties of Polyvinylpyrrolidone as is presented in Fig. 5.

The energies of the HOMO and LUMO, total energy $(\mathrm{E})$, number of transferred electrons $(\Delta \mathrm{N})$, softness $(\sigma)$, electrophilicity index $(\omega)$ and global hardness $(\eta)$ were calculated and are listed in Table 6:

The energy gap between the HOMO and LUMO is another important descriptor that must be considered. In Table 6, it is shown that the PVP inhibitor has a higher $E_{\mathrm{HOMO}}(-6.29 \mathrm{eV})$ energy and lower $E_{\mathrm{LUMO}}(1.01 \mathrm{eV})$ energy as well as a small energy gap $G_{\text {gap }} \sim-7.3 \mathrm{eV}$ between $E_{\mathrm{HOMO}}$ and $E_{\mathrm{LUMO}}$. This strengthens its inhibitory action on the C-steel surface. The electrophilicity index is another important parameter which shows the tendency of the molecule to accept electron(s). The charge transfer of $0.6 \mathrm{eV}$ indicates that the PVP inhibitor 
Table 6: HOMO and LUMO energies as well as the global reactivity indices $\mu, \sigma, \omega, \Delta N$, and $G_{\text {ap }}$ for Polyvinylpyrrolidone compound at the B3LYP/6-31G* level of theory.

\begin{tabular}{cccccccc}
\hline$E_{\mathrm{HOMO}}(\mathrm{eV})$ & $E_{\mathrm{LUMO}}(\mathrm{eV})$ & $\mu(\mathrm{eV})$ & $\eta(\mathrm{eV})$ & $\sigma\left(\mathrm{eV}^{-1}\right)$ & $\omega(\mathrm{eV})$ & $\Delta N(\mathrm{eV})$ & $G_{\mathrm{ap}}(\mathrm{eV})$ \\
\hline-6.29 & 1.01 & -2.65 & 3.65 & 0.27 & 0.96 & 0.6 & 7.3 \\
\hline
\end{tabular}

is a strong electron donor [3]. Generally, if the fractions of electrons transferred are less than $3.6 \mathrm{eV}$, the inhibition efficiency increases by increasing the electron donating capacity on the metal surface [51]. Softness $(\sigma)$ and chemical hardness $(\eta)$ are important chemical properties to measure molecular reactivity and stability. Therefore, the chemical reactivity increases as the inhibition efficiency of adsorption rises. Actually, the molecule with the smallest chemical hardness should exhibit the greatest inhibition efficiency [52]. The PVP inhibitor exhibits a good degree of chemical reactivity on the metal surface due to the decrease in the chemical hardness $(\eta=3.65$ $\mathrm{eV})$ and increase in the softness $\left(\sigma=0.27 \mathrm{eV}^{-1}\right)$.

\subsection{Inhibition mechanism}

Different techniques (Weight loss, SEM, and DFT) were used to determine the inhibitory effect of different molecular weights of Polyvinylpyrrolidone on the corrosion of $\mathrm{C}$-steel in a solution of perchloric acid. PVP58000 yielded the highest corrosion inhibition, while the monomer exhibited the lowest. The results showed that inhibition efficiencies on carbon steel increase as the concentration of the inhibitors (PVPs) rises and were enhanced following the addition of potassium iodide (KI) due to synergism. It is well known that iron exhibits coordinate affinity towards nitrogen-, sulfur- and oxygenbearing ligands [53]. In this study, the electron pairs of oxygen and nitrogen atoms are responsible for chemical bonding to the $\mathrm{C}$-steel surface.

\section{Conclusion}

The obtained results showed that Polyvinylpyrrolidone is effective in the presence of perchloric acid. The studied compounds exhibited good corrosion inhibition performances of PVP $\left(58,000 \mathrm{~g} \mathrm{~mol}^{-1}\right)$ on C-steel in perchloric acid and its activity increased as the concentration of the inhibitor rose, while the efficacy decreased as the temperature increased. The thermodynamic adsorption parameters show that the studied inhibitors are adsorbed on the C-steel surface following an exothermic, spontaneous process. Inhibition is achieved by the adsorption of the molecules on the C-steel surface and follows the Langmuir isotherm. The inhibition efficiency increased following the addition of iodide ions due to the synergistic effect and decreased by increasing the temperature. The SEM images illustrated the formation of a protective layer on the carbon-steel surface as well as supported the corrosion inhibition activity and synergistic effect. The inhibition efficiencies of the inhibitors obtained from the weight loss method and density functional theory are in good agreement.

\section{Acknowledgements}

The authors would like to express their gratitude to the University Abou Beker Belkaid Tlemcen and Higher School of Applied Sciences Tlemcen for their fruitful support.

\section{REFERENCES}

[1] Rasheeda, K.; Vijaya, D.P.A.; Krishnaprasad, P.A.; Samshuddin, S.: Pyrimidine derivatives as potential corrosion inhibitors for steel in acid medium-An overview, Int. J. Corros. Scale Inhib., 2018, 7(1), 48-61 DOI: 10.17675/2305-6894-2018-7-1-5

[2] Dwivedi, D.; Lepkova, K.; Becker, T.: Emerging surface characterization techniques for carbon steel corrosion: a critical brief review, Proc. R. Soc. A, 2017, 473(2199), 1-19 DOI: 10.1098/rspa.2016.0852

[3] Attar, T.; Benchadli, A.; Messaoudi, B.; Benhadria, N.; Choukchou-Braham, E.: Experimental and Theoretical Studies of Eosin Y Dye as Corrosion Inhibitors for Carbon Steel in Perchloric Acid Solution,Chem. React. Eng. Catal, 2020, 15(2), 454-464 DOI: $10.9767 / \mathrm{bcrec} .15 .2 .7753 .454-464$

[4] Bouraoui, M.M.; Chettouh, S.; Chouchane, T.; Khellaf, N.: Inhibition Efficiency of cinnamon oil as a green corrosion inhibitor, Journal of Bio and Tribo-Corrosion, 2019, 5(28), 1-9 DOI: 10.1007/s40735-019-0221-0

[5] Attar, T.; Larabi, L.; Harek, Y.: The Inhibition effect of potassium iodide on the corrosion of pure iron in sulfuric acid, $A d v$. Chem, 2014, 2014, 1-5 DOI: 10.1155/2014/827514

[6] Xhanari, K.; Finšgar, M.; Knez, Z.; Hrnčič, M.K.: Green corrosion inhibitors for aluminium and its alloys: a review, $R S C$ Adv., 2017, 7(44), 27299-27330 DOI: 10.1039/C7RA03944A

[7] Marzorati, S.; Verotta, L.; Trasatti, S.P.: Green Corrosion Inhibitors from Natural Sources and Biomass Wastes, Molecules, 2018, 24(1), 1-24 DOI: 10.3390/molecules 24010048

[8] Attar, T.; Benchadli, A.; Choukchou-Braham, E.: Corrosion inhibition of carbon steel in perchloric acid by potassium iodide, Int. J. Adv. Chem., 2019, 7(1), 35-41 DOI: 10.14419/ijac.v7i1.19651

[9] Azzam, E.M.S.; Abd El-Salam, H.M.; Reham, A.M.; Shaban, S.M.; Shokry, A.: Control the corrosion of mild steel using synthesized polymers based on polyacrylamide, Egypt. J. Pet., 2018, 27(4), 897910 DOI: 10.1016/j.ejpe.2018.01.006 
[10] Nawaz, M.; Yusuf, N.; Habib, S.: Development and Properties of Polymeric Nanocomposite Coatings, Polymers, 2019, 11(5), 1-14 DOI: 10.3390/polym 11050852

[11] Teodorescu, $\quad$ M.; $\quad$ Bercea, M.: Poly(vinylpyrrolidone)-A Versatile Polymer for Biomedical and Beyond Medical Applications, Polym. Plast. Technol., 2015, 54(9), 923-943 DOI: 10.1080/03602559.2014.979506

[12] Zhi, X.; Fang, H.; Bao, C.; Shen, G.; Zhang, J.: The immunotoxicity of graphene oxides and the effect of PVP-coating, Biomaterials, 2013, 34(21), 52545261 DOI: 10.1016/j.biomaterials.2013.03.024

[13] Jones, D.S.; Djokic, J.; Gorman, S.P.: The resistance of polyvinylpyrro-lidone-iodine-poly(ecaprolactone) blends to adherence of Escherichia coli, Biomaterials, 2005, 26(14), 2013-2020 DOI: 10.1016/j.biomaterials.2004.06.001

[14] Lgaz, H.; Salghi, R.; Ali, I.H.: Corrosion inhibition behavior of 9-hydroxyrisperidone as a green corrosion inhibitor for mild steel in hydrochloric acid: electrochemical, DFT and MD simulations studies, Int. J. Electrochem. Sci., 2018, 13(1), 250-264 DOI: 10.20964/2018.01.26

[15] Liu, S.B.: Conceptual density functional theory and some recent developments, Acta Phys. -Chim. Sin., 2009, 25(3), 590-600 DOI: 10.3866/pku.whxb20090332

[16] Aiad, I.; Shaban, S.; El-Sukkary, M.; El-Awady, M.; Soliman, E.: Electrical and Gravimetric Estimation of the Corrosion Inhibition of Three Synthesized Cationic Surfactants N-(3-(Butylidene Amino) Propyl)-N, N-Dimethyl Alkan-1-Ammonium Bromide Derivatives in $1 \mathrm{M} \mathrm{HCl}$, J. Mater. Eng., 2017, 6(1), 429-450 DOI: 10.1520/MPC20170001

[17] Attar, T.; Larabi, L.; Harek, Y.: Inhibition effect of potassium iodide on the corrosion of carbon steel (XC 38) in acidic medium, Int. J. Adv. Chem., 2014, 2(2), 139-142 DOI: 10.14419/ijac.v2i2.3272

[18] Javadian, S.; Yousefi, A.; Neshati, J.: Synergistic effect of mixed cationic and anionic surfactants on the corrosion inhibitor behavior of mild steel in 3.5\% NaCl, Appl. Surf. Sci., 2013, 285, 674-681 DOI: 10.1016/j.apsusc.2013.08.109

[19] Aslam, R.; Mobin, M.; Aslam, J.: Sugar based N,Ndidodecyl-N,Ndigluconamideethylenediamine gemini surfactant as corrosion inhibitor for mild steel in $3.5 \% \mathrm{NaCl}$ solution-effect of synergistic KI additive, Sci. Rep., 2018, 8, 3690 DOI: 10.1038/s41598-018-21175-6

[20] Eduok, U.M.; Umoren, S.A.; Udoh, A.P.: Synergistic inhibition effects between leaves and stem extracts of Sida acuta and iodide ion for mild steel corrosion in $1 \mathrm{M} \mathrm{H} 2 \mathrm{SO} 4$ solutions, Arab. J. Chem., 2012, 5, 325-337 DOI: 10.1016/j.arabjc.2010.09.006

[21] Pramudita, M.; Sukirno, S.; Nasikin, M.: Synergistic Corrosion Inhibition Effect of Rice Husk Extract and KI for Mild Steel in $\mathrm{H}_{2} \mathrm{SO}_{4}$ Solution, Bull.
Chem. React. Eng. Catal., 2019, 14(3), 697-704 DOI: 10.9767/bcrec.14.3.4249.697-704

[22] Shaju, K.S.; Thomas, K.J.; Raphael, V.P.; Paul, A.: Synergistic Effect of KI on Corrosion Inhibition of Mild Steel by Polynuclear Schiff Base in Sulphuric Acid, ISRN Corrosion, 2012, 2012, 1-8 DOI: 10.5402/2012/425878

[23] Roy, P.; Pal, A.; Sukul, D.: Origin of the synergistic effect between polysaccharide and thiourea towards adsorption and corrosion inhibition for mild steel in sulphuric acid, RSC Adv., 2014, 4(21), 10607 10613 DOI: 10.1039/c3ra46549g

[24] Hazazi, O.A.; Fawzy, A.; Awad, M.: Synergistic Effect of Halides on the Corrosion Inhibition of Mild Steel in $\mathrm{H} 2 \mathrm{SO} 4$ by a Triazole Derivative: Kinetics and Thermodynamic Studies, Int. J. Electrochem. Sci., 2014, 9, 4086-4103 http://electrochemsci.org

[25] Borghi, G.; Ferretti, A.; Nguyen, N.L.; Dabo, I.; Marzari, N.: Koopmans-compliant Functionals and Their Performance Against Reference Molecular Data, Phys. Rev. B, 2014, 90(7), 075135 DOI: 10.1103/physrevb.90.075135

[26] Pearson, R.: Absolute electronegativity and hardness: application to inorganic chemistry. Inorg. Chem., 1988, 27(4), 734-740 DOI: 10.1021/ic00277a030

[27] Benhadria, N.; Messaoudi, B.; Attar, T.: The Study of the Correlation between the Detection Limit and the Energy Stability of Two Antimony Complexes by Means of Conceptual DFT, Malaysian Journal of Chemistry, 2020, 22(2), 111-120 https://ikm.org.my/ojs/index.php/MJChem/article/view/609

[28] Yuan, S.; Liang, B.; Zhao, Y.; Pehkonen, S.: Surface chemistry and corrosion behaviour of 304 stainless steel in simulated seawater containing inorganic sulphide and sulphate-reducing bacteria, Corros. Sci., 2013, 74, 353-366 DOI: 10.1016/j.corsci.2013.04.058

[29] Chygyrynets, E.; Vorobyova, V.A.: Study of rapecake extract as eco-friendly vapor phase corrosion inhibitor, Chem. Chem. Technol., 2014, 8(2), 235242 DOI: 10.23939/chcht08.02.235

[30] Eddy, N.O.; Ita, B.I.: QSAR, DFT and quantum chemical studies on the inhibition potentials of some carbozones for the corrosion of mild steel in HCl, J. Mol. Model., 2011, 17(2), 359-376 DOI: 10.1007/s00894-010-0731-7

[31] Attar, T.; Messaoudi, B.; Benhadria, N.: DFT Theoretical Study of Some Thiosemicarbazide Derivatives with Copper, Chem. Chem. Technol., 2020, 14(1), 20-25 DOI: 10.23939/chcht14.01.020

[32] Benhadria, N.; Attar, T.; Messaoudi, B.: Understanding the Link Between the Detection Limit and the Energy Stability of Two Quercetin-Antimony Complexes by Means of Conceptual DFT, $S$. Afr. J. Chem., 2020, 73(1), 120-124 DOI: 10.17159/03794350/2020/v73a17

[33] Musa, A.Y.; Kadhum, A.A.H.; Mohamed, A.B.; Takriff, M.S.: Molecular dynamics and quantum 
chemical calculation studies on 4,4-dimethyl-3thiosemicarbazide as corrosion inhibitor in $2.5 \mathrm{M}$ $\mathrm{H}_{2} \mathrm{SO}_{4}$, Mater. Chem. Phys., 2011, 129(1-2), 660665 DOI: 10.1016/j.matchemphys.2011.05.010

[34] Alaoui, K.; El Kacimi, Y.; Galai, M.: New triazepine carboxylate derivatives: correlation between corrosion inhibition property and chemical structure, Int. J. Ind. Chem., 2020, 11(1), 23-42 DOI: 10.1007/s40090019-00199-5

[35] Popoola, L.T.: Organic green corrosion inhibitors (OGCIs): a critical review, Corros. Rev., 2019, 37(2), 71-102 DOI: 10.1515/corrrev-2018-0058

[36] Abd-El-Naby, B.A.; Abdullatef, O.A.; ElKshlan, H.M.; Khamisd, E.; Abd-El-Fatah, M.A.: Anionic Effect on the Acidic Corrosion of Aluminum and its Inhibition by Lupine Extract, Port. Electrochim. Acta, 2015, 33(5), 265-274 DOI: 10.4152/pea.201505265

[37] Singh, A.; Singh, A.K.; Quraishi, M.A.: A novel corrosion inhibitor for mild steel in acid media, Open. Electrochem. J., 2010, 2, 43-51 DOI: 10.2174/1876505X01002010043

[38] Chakravarthy, M.P.; Mohana, K.N.: Adsorption and Corrosion Inhibition Characteristics of Some Nicotinamide Derivatives on Mild Steel in Hydrochloric Acid Solution, Int. Sch. Res., 2014, 2014, 1-13 DOI: 10.1155/2014/687276

[39] Oguzie, E.E.: Studies on the inhibitive effect of Occimumviridis extract on the acid corrosion of mild steel, Mater. Chem. Phys., 2006, 99(2-3), 441-446 DOI: 10.1016/j.matchemphys.2005.11.018

[40] Eddy, N.O.; Odoemelam, S.A.; Odiongenyi, A.O.: Inhibitive, adsorption and synergistic studies on ethanol extract of Gnetum africana as green corrosion inhibitor for mild steel in $\mathrm{H}_{2} \mathrm{SO}_{4}$, Green. Chem. Lett. Rev., 2009, 2(2), 111-119 DOI: 10.1080/17518250903170868

[41] Chakravarthy, M.P.; Mohana, K.N.; Pradeep Kumar, C.B.: Corrosion inhibition effect and adsorption behaviour of nicotinamide derivatives on mild steel in hydrochloric acid solution, Int. J. Ind. Chem., 2014, 5(2), 1-21 DOI: 10.1007/s40090-014-0019-3

[42] Benchadli, A.; Attar, T.; Choukchou-Braham, E.: Inhibition of Carbon Steel Corrosion in Perchloric Acid Solution by Povidone Iodine, Phys. Chem. Res., 2019, 7(4), 837-848 DOI: 10.22036/PCR.2019.198787.1665

[43] Umoren, S.A.; Obot, I.B.; Ebenso, E.E.: Corrosion Inhibition of Aluminium Using Exudate Gum from Pachylobus edulis in the Presence of Halide Ions in $\mathrm{HCl}$, Eur. J. Chem., 2008, 5, 355-364 DOI: 10.1155/2008/138407

[44] Faustin, M.; Maciuk, A.; Salvin, P.; Roos, C.; Lebrini, M.: Corrosion inhibition of $\mathrm{C} 38$ steel by al- kaloids extract of Geissospermum laeve in 1M hydrochloric acid: Electrochemical and phytochemical studies, Corros. Sci., 2015, 92, 287-300 DOI: 10.1016/j.corsci.2014.12.005

[45] Fawzy, A.; Abdallah, M.; Zaafarany, I.A.; Ahmed, S.A.; Althagafi, I.I.: Thermodynamic, kinetic and mechanistic approach to the corrosion inhibition of carbon steel by new synthesized amino acids-based surfactants as green inhibitors in neutral and alkaline aqueous media, J. Mol. Liq., 2018, 265(1), 276291 DOI: 10.1016/j.molliq.2018.05.140

[46] Umoren, S.A.; Obot, I.B.; Ebenso, E.E.; ObiEgbed, N.O.: Synergistic Inhibition between Naturally Occurring Exudate Gum and Halide Ions on the Corrosion of Mild Steel in Acidic Medium, Int. J. Electrochem. Sci., 2008, 3(9), 1029-1043 http://citeseerx.ist.psu.edu

[47] Attar, T.; Larabi, L.; Harek, Y.: Corrosion inhibition of cold rolled steel in $0.5 \mathrm{M} \mathrm{H}_{2} \mathrm{SO}_{4}$ by potassium iodide, Der Pharma Chemica, 2014, 6(4), 181-186 https://www.derpharmachemica.com

[48] Benchadli, A.; Attar, T.; Choukchou-Braham, E.: Corrosion inhibition of carbon steel (XC 38) in hydrochloric acid by potassium iodide, Journal of Advanced Research in Science and Technology, 2018, 5(2), 834-844 https://www.asjp.cerist.dz

[49] Doner, A.; Solmaz, R.; Ozcan, M.; Kardas, G.: Experimental and Theoretical Studies of Thiazoles as Corrosion Inhibitors for Mild Steel in Sulphuric Acid Solution, Corros. Sci., 2011, 53(9), 2902 2913 DOI: 10.1016/j.corsci.2011.05.027

[50] Solmaz, R.: Investigation of corrosion inhibition mechanism and stability of Vitamin B1 on mild steel in 0.5M HCl solution, Corros. Sci., 2014, 81, 75-84 DOI: 10.1016/j.corsci.2013.12.006

[51] Lukovits, I.; Kalman, E.; Zucchi, F.: Corrosion Inhibitors-Correlation between Electronic Structure and Efficiency, Corrosion, 2001, 57(1), 3-9 DOI: 10.5006/1.3290328

[52] Ramya, K.; Mohan, R.; Joseph, A.: Adsorption and electrochemical studies on the synergistic interaction of alkyl benzimadazoles and ethylene thiourea pair on mild steel in hydrochloric acid, J. Taiwan. Inst. Chem. Eng., 2014, 45(6), 3021-3032 DOI: 10.1016/j.jtice.2014.08.033

[53] Bentiss, F.; Jama, C.; Mernari, B.: Corrosion control of mild steel using 3,5-bis(4-methoxyphenyl)4-amino-1,2,4-triazole in normal hydrochloric acid medium, Corros. Sci., 2009, 51(8), 1628-1635 DOI: 10.1016/j.corsci.2009.04.009 